\title{
O CURRÍCULO DA PASTORAL DA JUVENTUDE E A CONSTITUIÇÃO SUBJETIVA DO JOVEM CATÓLICO
}

\author{
Valdecy de Souza Meirelles ${ }^{1}$ \\ Wladirson R. da S. Cardoso ${ }^{2}$
}

\begin{abstract}
RESUMO
O presente texto aborda reflexões acerca da constituição do sujeito/jovem a partir dos documentos da pastoral da juventude. A pesquisa tem como objetivo analisar a constituição do discurso presente no currículo da pastoral da juventude como forma de subjetivação e objetivação dos jovens. Este estudo se estrutura a partir da análise dos documentos da CNBB - Conferência Nacional dos Bispos do Brasil, que trata sobre a evangelização da juventude, que são: documento 44 (1986), documento 85, (2007), Somos Igreja Jovem (2012), no qual está contido o projeto Tecendo Relações. Foi realizada a análise do discurso presente nesses documentos para que se possa compreender o processo de objetivação e subjetivação dos jovens. Subsidiará a pesquisa os escritos de Foucault. O procedimento metodológico utilizado na pesquisa foi pesquisa/leitura bibliográfica para análise do discurso pastoral, contidos nos documentos pastorais.
\end{abstract}

Palavras chaves: Sexualidade; Pastoral; Juventude.

\begin{abstract}
This text addresses reflections on the constitution of the subject / youth from the documents of youth ministry. The research aims to analyze the constitution of the discourse present in the curriculum of youth ministry as a form of subjectivation and objectification of young people. This study is structured from the analysis of the documents of the CNBB - National Conference of Bishops of Brazil, which deals with the evangelization of youth, which are: document 44 (1986), document 85, (2007), Somos Igreja Jovem (2012), which contains the project Tecendo Relations. The analysis of the discourse present in these documents was performed so that the process of objectification and subjectification of young people can be understood. The research will support Foucault's writings. The methodological procedure used in the research was bibliographic research / reading for analysis of pastoral discourse, contained in pastoral documents.
\end{abstract}

Keywords: Sexuality; Pastoral; Youth.

\section{INTRODUÇÃO}

O projeto Tecendo Relações apresenta diretrizes que orientam como a Pastoral da Juventude deve trabalhar com a juventude temas como: sexualidade, afetividade e gênero. Para uma melhor organização do trabalho, as investigações sobre esse universo visam restringir o campo de pesquisa em uma análise do discurso presente nos documentos pastorais

\footnotetext{
${ }^{1}$ Universidade Federal do Pará. Pedagogo e Mestre em Currículo e Gestão da Escola Básica PPEB/NEB- UFPA. E-mail: lucaejoao@hotmail.com

${ }^{2}$ Doutor em Antropologia Social e Pós Doutor em Currículo. Professor do CCSE/DFCS/PPGCR - UEPA e NEB/PPEB - UFPA. E-mail: wladirson.cardoso@gmail.com
} 
que tratam sobre a evangelização da juventude para assim compreender o discurso na prática da Pastoral da Juventude a partir do projeto Tecendo Relações.

Para obtenção dos resultados da pesquisa foi realizada a análise documental da formação discursiva presente no currículo da Pastoral da Juventude como forma de objetivação e subjetivação dos jovens a partir do projeto Tecendo Relações, Documento 44 e Documento 85. Pretende-se assim, responder a seguinte indagação: Como o currículo da Pastoral da Juventude tem contribuído no processo de objetivação e subjetivação dos jovens?

Consonante a esta indagação a análise feita do currículo pastoral tem como objetivo identificar as normas religiosas, a partir de diferentes aspectos, visto que ele está relacionado às formações ideológicas e discursivas do clero. Neste sentido, considera-se o discurso religioso cristão católico a base da formação da Pastoral da Juventude já que em seus documentos - Documento 44 (1986), Documento 85 (2007) e Somos Igreja Jovem (2012) -, está escrito que os jovens necessitam de formação em todos os seus aspectos, não apenas espiritual, mas social, política e psicoafetiva. De acordo com esses documentos a formação discursiva da Pastoral da Juventude propõe equilíbrio pessoal, intelectual e de integração consciente do jovem ao mundo em que está inserido. Ao analisar esses documentos percebese que ao longo da história da igreja católica, a formação oferecida por essa instituição teve único objetivo disciplinar e normalizar o indivíduo de acordo com as normas préestabelecidas na sociedade em que estava inserido.

Nesse contexto, a igreja ocupa lugar privilegiado no sentido de se constituir enquanto instituição que exclui, origina padrões claramente estabelecidos e regulados para cada um/uma de seus/suas fiéis, tornando-se, portanto, espaço de produção e reprodução de preceitos morais e regulatórios, através de uma ótica sexista e heteronormativa. Um bom exemplo é a sexualidade que, apesar de ser muito discutida fora do espaço religioso, ainda é tabu dentro das igrejas e nos discursos dos padres, pastores, religiosos e religiosas, seja por preconceitos ou por preceitos morais.

É nesse sentido, que, a igreja impõe papéis pré-estabelecidos para homens e mulheres, não levando em consideração as diferenças individuais dos sujeitos, que são inerentes aos papéis de gênero e à própria história de vida de cada um/uma.

Dessa maneira, interesses e formas de comportamento para cada sujeito são estimulados no ambiente pastoral, por isso, é necessário perceber, como esses comportamentos são formados e legitimados, fazendo com que os jovens se identifiquem ou se diferenciem de acordo com as características socialmente valorizadas e/ou determinadas. De acordo com os documentos analisados, a constituição do sujeito pastoral encontra-se 
relacionadas às formas discursivas como a igreja concebe os diferentes papéis sociais e comportamentais de homens e mulheres, estabelecendo padrões fixos daquilo que é próprio para o feminino bem como para o masculino, de forma a reproduzir regras como se fosse comportamento natural do ser humano, originando condutas e modos únicos de viver.

Nesse contexto a igreja contribui na produção e reprodução de sujeitos, quando institui gestos, condutas e posturas apropriadas a cada um/uma. Através de um longo processo catequético cada um vai sendo colocado em seu lugar. Menino e menina, jovens, mulheres e homens entre outras tantas posições de sujeito.

A pesquisa apresenta narrativas e reflexões sobre o discurso pastoral presente nos documentos de evangelização da juventude elaborado pela Igreja católica. A pesquisa visa investigar a constituição do discurso presente nos documentos da Pastoral da Juventude e a sua contribuição no processo de subjetivação e objetivação dos Jovens idealizados por essa pastoral.

A investigação fundamenta-se nos estudos de FOUCAULT (2000, 2006, 2007, 2009), CNBB (1986, 1992, 1998, 2007,2010, 2012), BORAN (1985). A partir dos aportes teóricos foram identificadas as práticas discursivas dos jovens integrantes da Pastoral da Juventude para compreender os enunciados que atravessam essa produção discursiva. Também foi revelado como a construção do discurso da Pastoral da Juventude está ligado ao currículo elaborado pela igreja católica, o que contribui no processo de subjetivação e objetivação dos jovens. Foi feito um percurso histórico sobre a constituição do discurso pastoral, as bases teóricas do currículo pastoral e o processo de constituição do sujeito jovem, apresentados nos documentos pastorais.

Nesse sentido, no decorrer da pesquisa se busca valorizar os contextos abrangentes, as subjetividades, aquilo que será revelado pelas experiências e vivências e não mais somente o que pode ser mensurado evidenciado por dados técnicos.

\section{PROCESSO DE EDUCAÇÃO NA FÉ - O CAMINHO CURRICULAR DA PASTORAL DA JUVENTUDE}

A proposta pedagógica da pastoral da Juventude baseia-se no entendimento do jovem enquanto sujeito da ação evangelizadora, a serviço da animação e organização das comunidades eclesiais atuantes nos diferentes espaços da sociedade, para tanto, a Pastoral da Juventude, sistematizou no decorrer de sua história, as dimensões da formação integral e o processo de educação na fé, as quais estão presentes e orientam as ações pedagógicas que 
norteiam o seu as práticas da Pastoral, como por exemplo, a importância do grupo de jovens na vida do próprio jovem e da igreja, a formação integral, a memória, o trabalho que desenvolve com os diferentes tipos de jovens, sua organização, a importância do acompanhamento, a vocação e, por fim a elaboração do projeto de vida.

Como se pode, então, vislumbrar, a ação pedagógica da pastoral da juventude tem como objetivo fazer com que o jovem seja formado em sua plenitude. Para isso, a formação integral do jovem, sustenta-se em cinco dimensões da pessoa humana: personalização, integração, evangelização, conscientização e capacitação. Através dessa proposta pedagógica, a pastoral da juventude desenvolve com os jovens o processo de formação integral, buscando ajudá-los a ser plenamente a que é chamado. E, na sua visão, o jovem é chamado a ser pessoa a imagem e semelhança de Deus, segundo o modelo de Jesus Cristo, liberto, fraterno, criativo, sujeito da história. Desenvolver o processo de formação integral do jovem, implica pedagogicamente para a pastoral da juventude, trabalhar cada uma das dimensões da pessoa humana - vide documento 44 (1986), documento 85, (2007), Somos Igreja Jovem (2012), da CNBB-Conferência Nacional dos Bispos do Brasil.

Para realizar o processo de formação integral do jovem, a pastoral da juventude, tem como instrumento pedagógico principal o grupo de base. Nesse grupo, mediante a dialética ação-reflexão, os jovens deverão explicitar seu encontro pessoal e comunitário com o Cristo vivo para que evangelizados, evangelizem e se comprometam com a libertação integral do homem e da sociedade.

A pastoral de juventude, nas experiências das ações desenvolvidas fez uma opção metodológica entre os diferentes procedimentos existentes. Houve uma opção clara pelo método da ação católica conhecido como "ver-julgar-agir", acrescido com o tempo pelo "revisar" e "celebrar". A metodologia indutiva parte da realidade da vida, da prática concreta para depois confrontar suas conclusões com a teoria, a doutrina. Esta metodologia obriga a teoria adaptar-se à realidade concreta, e provocar nova reflexão e ação para que a vida seja encarnada com o senso crítico e engajamento. Esse modelo de metodologia utilizado pela Pastoral da Juventude é também a metodologia utilizada pela CNBB, para o planejamento pastoral.

Através desse método, a pastoral da juventude terá condições de analisar todos os aspectos da juventude, para conhecer a realidade que circunda os jovens, conhecendo a realidade a igreja pode controlá-los e por meio do processo de formação integral pode discipliná-los. 
A evangelização dos jovens terá sucesso à medida que responda globalmente as necessidades e aspirações dos mesmos. Por isso do ponto de vista pedagógico, é importante que o anúncio evangélico e a catequese não sejam realizados apenas de forma abstrata, mas dentro de um contexto vivencial e por meio de paciente e constante acompanhamento (CNBB, 1986, p. 23)

Assim, a pastoral da juventude fez a opção pelo planejamento pastoral, pela leitura orante da bíblia, pelo método da ação católica e da igreja latina americana. De acordo com esses princípios pedagógicos elaborou eixos de ação que irão nortear todo o fazer pedagógico pastoral, que são: formação, ação, espiritualidade e articulação. Uma das experiências práticas da efetivação da estrutura curricular da Pastoral da Juventude é o projeto Tecendo Relações que se caracteriza de acordo com os anseios dos jovens, nas vivências dos grupos de base ou fora deles.

A igreja católica aconselha que toda ação com os jovens considere as questões ligadas à efetividade e sexualidade apontando para a necessidade de se trabalhar com todas as dimensões da pessoa. Na formação para o discipulado é necessário partir de uma formação integral, considerando as cincos dimensões da pessoa humana: psicoafetiva, psicossocial, mística, sócio-política-ecológica e capacitação. Trata-se de efetivar, pedagogicamente, um conceito que se encaixa no contexto da sensibilidade da cultura jovem e aponta para uma nova síntese que integre o racional com o simbólico, a efetividade, o corpo a fé e o universo.

O projeto Tecendo Relações que se encontra no documento intitulado Somos Igreja jovem (2012), visa colaborar na construção da identidade dos jovens que desejam aprofundar as temáticas da sexualidade, afetividade, diversidade e corporeidade. Para tanto, o referido projeto tem como iniciativas:

1. Contribuir para a defesa da dignidade da pessoa humana e para a construção de relações respeitosas amorosas, igualitárias, dialógicas e horizontais (CNBB,2012, p.12).

2. Promover espaços de diálogo e partilha sobre as experiências afetivas (CNBB, 2012, p.12).

3. Aprofundamento do projeto a partir dos documentos da igreja (CNBB,2012, p.12).

4. Conhecer a história da sexualidade e os diversos estudos sobre a temática (CNBB,2012, p.12).

5. Sistematizar algumas experiências de trabalho sobre a questão de gênero e juventude (CNBB,2012, p.12-13).

6. Aprofundar temas como corporeidade, violência de gênero, a violência contra mulher e a violência sexual, de forma articulada com as ações da campanha contra a violência e o extermínio de jovens (CNBB,2012, p.13). 
7. Favorecer reflexões para que os jovens pensem seu projeto de vida, considerando a dimensão da afetividade e sexualidade (CNBB,2012, p.13).

8. Estimular o combate aos preconceitos nas diferentes formas em que se manifesta (CNBB,2012, p.14).

Metodologicamente, o trabalho do projeto Tecendo Relações exige formação com profissionais da área e agentes de pastoral com conhecimentos das temáticas abordadas e a criação de espaços que possibilitem diálogo e vivência, como rodas de conversas, biodanças, músicas, poesias, dinâmicas, teatro dentre outros.

\section{BASES DA FORMAÇÃO DISCURSIVA DA PASTORAL DA JUVENTUDE}

Para fundamentar a constituição dos dispositivos disciplinares de subjetivação que, por sua vez, são objetivados em textos e documentos reguladores das ações da pastoral, recorremos a Foucault (2006), que afirma que o discurso se constitui historicamente nas diferentes relações, de modo que estas conferem ao discurso propriamente dito a materialidade de que se pode falar e determinam a quantidade de relações em si mesmas, as quais o discurso, por sua vez, pode realizar.

Segundo Foucault (2006), sujeito e objeto só passam a existir a partir de uma prática discursiva entre ambos. Portanto, de acordo com esse autor o discurso é construído historicamente e socialmente, através de proposições do saber como forma de aquisição do poder, visto que, o discurso não possui uma dimensão rígida, inalterada, pronta, estável, por isso modifica-se de acordo com o movimento histórico.

Nesse sentido as formações discursivas são formadas por práticas discursivas, levando-se em consideração as diferentes relações que elas acontecem, assim como também as diferentes épocas que são produzidas, pois tais discursos são produzidos a partir de determinado lugar social, ou seja, todo discurso produzido está relacionado a outros discursos existentes anteriormente.

Assim podemos considerar que a produção do discurso envolve elementos discursivos e não discursivos como leis, instituições acontecimentos políticos, econômicos culturais e outros, assim: 
A identidade de um enunciado está submetida a um segundo conjunto de que deve desempenhar condições e de limites: os que lhes são impostos pelo conjunto dos outros enunciados no meio dos quais figura; pelo domínio no qual podemos utilizálo ou aplica-lo; pelo papel ou função (FOUCAULT, 2006, p.119).

Tendo como objeto de análise o discurso da igreja católica, estes estão submetidos aos momentos históricos aos quais são produzidos de acordo com os objetivos e as necessidades desta instituição religiosa e, isso se concretiza através de elementos como os dogmas, a bíblia e os documentos oficiais da igreja. De posse desses elementos a Pastoral da Juventude produz seu discurso que se consolida por meio do processo de formação integral no qual estão contidas as regras das práticas cristãs católicas.

De acordo com o pensamento foucaultiano, o sujeito se constitui com os acontecimentos discursivos, epistêmico e práticos que se explicitam nos vários tipos de discursos, dentre eles o discurso religioso, influenciado por aqueles que exercem os poderes econômicos, midiáticos, político, religioso e cultural. Isso quer dizer que, o sujeito (no caso o Jovem) da Pastoral da Juventude se constitui historicamente através de elementos anteriores, exteriores e posteriores a ele, como, por exemplo, o discurso bíblico, o discurso doutrinário, o discurso da moral religiosa que é perpassado por meio do processo de formação e evangelização da juventude. É através desses elementos que se constitui o sujeito pastoral e ocorre o processo de objetivação e subjetivação dos jovens.

Nos anos de 1980, aderir à formação discursiva da Pastoral da Juventude implicava constituir-se como sujeito da Pastoral em um processo de subjetivação que identificava, classificava e fazia desse jovem o seu porta-voz e, consequentemente da igreja católica. Esse processo de construção do sujeito pode ser observado pelos enunciados nos fragmentos do documento 44 .

a) os jovens se encontram na etapa em que se fazem as grandes opções, que decidem o futuro de sua vida. [...], são as grandes vítimas de uma estrutura social injusta (CNBB, 1986, p.8).

b) A igreja "apoiará" os jovens, principalmente das bases populares, a tomarem consciência de que são marginalizados por estruturas sociais desagregadoras (CNBB, 1986, p.10).

C). É necessário formar os jovens [...], para a ação sociopolítica e para as mudanças de estruturas, de menos humanas em mais humanas, segundo a doutrina social da igreja (CNBB, 1986, p.14).

d) A igreja quer provocar e acolher os jovens, pois ela mesma precisa sentir-se jovem, para apresentar-se jovem ao mundo como sinal de libertação integral, esperança e alegria. (CNBB, 1986, p.15) 
e) Os jovens são, pois, convocados a desenvolver um amor pessoal e comunitário [...], a Jesus Cristo, consagrando a própria vida à construção do reino de Deus. (CNBB, 1986, p.17)

F). É necessário que a presença cristã não se contente em representar-se politicamente pelo voto, mas assume o compromisso profético transformador (CNBB, 1986, p.35).

g) O jovem descobre [...], que Jesus Cristo viveu situado na sociedade de seu tempo. Seu projeto de vida foi a corajosa tomada de posição na defesa de valores que conflitavam com os critérios sociopolíticos - religioso da época (CNBB, 1986, p.41).

O sujeito proposto pela Pastoral da Juventude, a partir da compreensão desses enunciados, é um sujeito implicado no controle, uma vez que está submetido às posições discursivas pastorais, pois mesmo se "reconhecendo" como o principal ator da evangelização, ele está submetido à pratica discursiva da Pastoral de Juventude, já que ao atender a convocação da Pastoral da Juventude, ele deverá consagrar a própria vida à construção do Reino de Deus.

De acordo com os enunciados, os jovens serão objetos de evangelização, visto que a igreja católica não visa apenas seu bem-estar, mas principalmente a sua promoção enquanto instituição junto a sociedade, uma instituição milenar cujos valores antigos ainda persistem e resistem, por isso vê nos jovens uma forma de se transformar, usando-os como instrumento de renovação de suas práticas discursivas.

Para a Pastoral da Juventude, se reconhecer como sujeito e protagonista é uma estratégia para o indivíduo não se tornar alienado aos poderes constituídos fora da ordem discursiva religiosa. Sob a influência dos ensinamentos cristãos propostos pela pastoral, o jovem será subjetivado nesta instituição, ou seja, transformado pela pastoral o jovem reproduz o discurso religioso cristão, pautado nos ensinamentos catequéticos, pois se insere em uma dada formação discursiva que o faz reproduzir em sua prática discursiva dizeres de um período histórico que ele não viveu. Em toda formação discursiva há um sujeito que fala a partir das condições históricas - sociais que a permeia.

A formação discursiva religiosa da Pastoral da Juventude na década 1980 é atravessada por condições sócio-políticas, uma vez que a maioria dos sujeitos, no seu processo de formação, é historicamente engajada nas lutas políticas, principalmente dos movimentos estudantis da década de 1960 e 1970. Por isso a Pastoral da Juventude, com esse método pedagógico de opções religiosas, sociais e políticas, pauta-se no processo de formação integral. Segundo os enunciados do documento 44, a formação integral deve levar o jovem a 
uma tomada de posição política, sendo que o mesmo deve conhecer as estruturas políticas para discernir entre aquela que melhor expressa o caminho que deve seguir.

De acordo com o que enuncia o documento 44 acerca dos jovens e suas condições socioeconômicas, estes são considerados marginalizados e excluídos, por isso apresenta os jovens como: as grandes vítimas, criminosos, são obrigados a trabalhar, são condenados ao desemprego, desesperados entregam-se ao jogo, drogas, alcoolismo, promiscuidade, desfigurado e violentado em sua dignidade. Essa caracterização dos jovens no documento 44 reafirma a necessidade de serem conduzidos, por isso, é preciso que haja alguém ou alguma instituição capaz de orientá-los. Diante disso, a Pastoral da Juventude se coloca como a instituição capaz de transformar a situação da juventude.

Segundo postulados da Pastoral da Juventude, o jovem é o sujeito da ação evangelizadora, pois pretende que este se coloque a serviço das comunidades em diferentes espaços onde a juventude atua. Essa questão fica clara no documento 44, ao analisarmos a afirmação que define o segundo objetivo básico assumido pela Pastoral da Juventude na década de 1980: "Impulsionar o jovem a que, na medida em que se evangeliza, evangelize e transforme seu meio específico de acordo com os valores cristãos" (CNBB, 1986, p.21).

A partir desse enunciado, bem como do perfil de juventude nele construído, o jovem será objeto de disseminação da evangelização da Pastoral da Juventude. Esse enunciado denota a objetivação do jovem no documento, pois delimita uma proposta de um tipo de sujeito, o sujeito pastoral.

Nesse contexto, o jovem será também subjetivado, ou seja, tornar-se-á sujeito da evangelização, ao mesmo tempo em que será objeto de evangelização. Tomando como base a concepção Foucautiana sobre a constituição do sujeito, ao ser subjetivado, o jovem deverá reconhecer como sua a identidade pastoral, enquanto como objeto de evangelização, constituise em um objeto dócil e útil, neste caso específico útil à igreja. Esta afirmação se encontra no documento 44, quando fala sobre a formação do jovem: "Deve-se organizar um processo de formação diferenciado, o que importa é dar os passos pedagógicos necessários para levar o jovem a um compromisso com Jesus Cristo e com o homem sofrido de hoje." (CNBB, 1986, p.31).

A evangelização nos moldes da igreja católica na década de 1980 visava a conduzir o jovem à participação social, minimizando as dores do homem sofrido para que este seja transformado e reconheça doutrina cristã como a ideal. Assim, ao evangelizar o jovem, a Pastoral da Juventude - ou a PJ como se chama a partir da sigla - condiciona a transformação da vida dele aos princípios da evangelização cristão-católica. 
Há também uma relação entre saber e poder no enunciado acima, visto que a proposta de evangelização da PJ pressupõe obter conhecimento para adquirir poder. Sobre a relação entre saber e poder, Foucault (2006), afirma que este se exerce e, por meio daquele é possível exercer poder, pois, ao se valer de um determinado saber, os sujeitos o utilizarão como estratégia de poder para influenciar as condutas de outros sujeitos.

O jovem é objetivado nas diretrizes da PJ ao assumir a condição de membro da pastoral, pois ele constitui sujeito discursivo da PJ, e é transformado pelo processo de formação da PJ e assumirá uma identidade segundo os ensinamentos da PJ. Simultaneamente, o jovem será objetivado pela PJ como alguém que precisa de cuidado, transformado pela instituição, e logo subjetivado por meio de um processo formador, porque assumirá essa identidade para si, construída pela prática discursiva da PJ.

As diretrizes gerais do documento 44 abaixo apontam a constituição de processos de subjetivação dos jovens que aderirem aos postulados religiosos:

\footnotetext{
A Pastoral da Juventude deve auxiliar os jovens e assessores a aprofundar os projetos políticos e os princípios cristãos que vão nortear opções concretas (CNBB, 1986, p.35).
}

\begin{abstract}
A Pastoral da Juventude deve buscar uma pedagogia que responda à necessidade de se criar um espaço próprio para os jovens empobrecidos dentro de uma pastoral orgânica da juventude levar o jovem a perceber que sua recusa a uma espiritualidade cristã frequentemente resulta da falsa compreensão da mesma. O que ele rejeita é uma espiritualidade incompleta, desencarnada e descomprometida com a realidade (CNBB, 1986, p.39).
\end{abstract}

Incentivar o engajamento dos jovens nos meios específicos da sociedade e nos seus organismos intermediários (sindicatos, movimentos populares, associações de bairro, partido político, movimento estudantil, grêmio estudantil), para que seja fermento evangélico de transformação (CNBB, 1986, p.46).

As diretrizes acima demonstram que o discurso da PJ na década de 1980 aponta para uma subjetivação do jovem, que deve se tornar sujeito da PJ no processo de evangelização. Estes enunciados típicos da formação discursiva religiosa cristã visam incentivar o jovem a se deslocar a serviço da evangelização segundo a Igreja Católica.

O documento também alia dizeres do discurso religioso a ditos políticos para estabelecer uma relação de poder entre valores do Reino de Deus e do homem - neste contexto o jovem - relação esta que deve acontecer pela espiritualidade. De acordo com Foucault (2000; 2006; 2007), o documento permite a possibilidade de coexistência, visto que é construído historicamente e retoma outros enunciados produzidos anteriormente. Com isso, o discurso produzido pela PJ na década de 1980 apresenta aspectos de sua historicidade e 
reafirma a "opção preferencial pelos jovens e pelos pobres" que a igreja católica assumiu na conferência Episcopal Latino Americana, em 1979, na cidade de Puebla, México (CELAM, 1979, p.365).

Sendo assim, o discurso da PJ é um discurso limitado, controlado pelos pressupostos cristãos, políticos e culturais daquela época. Os jovens, envolvidos no processo de catequização pastoral, são conduzidos a fazerem parte da história da PJ para que a assumam como parte de sua identidade e lutem por ela. Com isso, enquanto responsável pela existência e pelo crescimento da organização, a Igreja Católica, por meio dos líderes da PJ (lideranças, jovens, bispos, padres, freiras, et...) almeja que os jovens da PJ se sintam motivados a permanecer e a transformar esse espaço.

Ao optar pela participação na Pastoral da Juventude, estes jovens escolhem um estilo de vida peculiar em que deverão seguir alguns preceitos que determinarão suas posturas, seus comportamentos e influenciarão seu ato de fala, através do processo de formação integral da Pastoral da Juventude.

Por meio do processo de formação a Pastoral da Juventude, pretende que os jovens se reconheçam no espaço discursivo e ocupem determinadas posições de sujeitos evangelizadores, formadores de consciência- sociopolítica, a partir dos preceitos cristãos católicos. O contexto sócio-político religioso influencia ações da Igreja Católica e assim os movimentos de práticas neopentecostais crescem no interior dela. Essas condições são determinantes para definir as práticas discursivas da Igreja Católica neste século. Com isso, o documento 85 Evangelização da Juventude, desafios e perspectivas pastorais, publicado pela CNBB em 2007, reproduz enunciados que envolvem elementos da pós-modernidade, a subjetividade, a centralidade das emoções, as novas tecnologias, o individualismo e a ausência de luta coletiva que indicam outra conjuntura, porém um desafio para a Igreja Católica. A própria Igreja Católica assume tais condições e, por consequência, a sua dificuldade de se adaptar aos "novos tempos", quando afirma que "num primeiro momento, a igreja fragilizouse ao resistir à possiblidade de mudanças, distanciando-se da juventude, da sua linguagem de suas expressões e maneiras de ser e viver diante do avanço da modernidade" (CNBB, 2010, p.16).

Há diversas tendências de evangelização dentro da igreja católica. Os enunciados produzidos pela Pastoral da Juventude têm diferentes sentidos se proferidos por sujeitos ligados a outras tendências como a renovação carismática (RCC), que se destaca a partir dos anos de 1990 com uma prática discursiva que se pauta nos princípios neopentecostais e acentuam a subjetividade e a afetividade em sua metodologia de evangelização, em 
detrimento do compromisso social e político, conforme podemos notar nas palavras do documento 85:

\begin{abstract}
O modelo de capitalismo neoliberal, a tendência de acentuar os sentimentos no mundo contemporâneo, tem forte penetração no meio dos jovens e levanta questões importantes referentes à metodologia de trabalho pastoral. Por outro lado, à medida que aumenta o nível de escolaridade dos jovens, aumenta também, a necessidade de uma base intelectual da fé, caso contrário muitos acabam abandonado sua fé. É importante lembrar que as duas culturas continuam convivendo juntas; a modernidade, que acentua a razão, e a pós-modernidade, que acentua a centralidade das emoções (CNBB, 2010, p.22).
\end{abstract}

Agora, o documento 85, dadas as condições de produção, assume que a Pastoral da Juventude, fortalecida na década de 1980, não atende aos anseios da igreja católica e do atual momento histórico político da sociedade. Com isso, a igreja assume que,

Hoje é mais fácil trabalhar a espiritualidade, em todas as suas dimensões do que na década de 1980, quando o tempo dedicado às celebrações e à oração era frequentemente visto como algo secundária face à urgência da transformação social (CNBB, 2010, p.20).

O uso do termo "hoje" reforça que esse momento da enunciação é diferente daquele em que o documento anterior (Doc. 44), enunciava, reafirmando que as condições de produção nesse momento histórico privilegiam o discurso de valorização do sentimento, em detrimento dos enunciados políticos-religiosos da década de 1980. O marcador temporal demonstra, contudo, a adequação do discurso da igreja católica às exigências de um dado momento histórico.

Apesar das mudanças nas práticas discursivas da igreja católica uma questão permanece, conforme demonstrado nas análises do documento 44. O jovem continua sendo objetivado como sujeito que deve contribuir para o crescimento da igreja católica: “jovem [...] contribuam com ação de toda a igreja" (CNBB, 2010, p.11).

Outra marca particular do documento 85 , diferente do documento 44 , refere-se à ampla retomada dos dizeres bíblicos. De forma recorrente em seu texto, o documento 85, apresenta citações bíblicas como forma de referenciar seu discurso, sem recorrer a outra doutrina como acontece no discurso do documento 44, que se pauta em enunciados bíblicos e políticos. No documento 44 os dizeres bíblicos são reatualizados para a condução da participação política como projeto social de Jesus Cristo, que se posicionava contra o sistema político, ao passo que, nas diretrizes do documento 85 , essa referência discursiva não ocorre. 
A aplicação dos enunciados presentes nos documentos demonstra as características da formação discursiva de cada época e a adequação do discurso e da prática discursiva da Igreja Católica no tocante à evangelização da juventude. Segundo Foucault (2000), o enunciado enquanto função enunciativa relaciona as unidades com um campo de objetos, pois há um referente que se alia a um conjunto de posições subjetivas e as coloca em domínio de coordenação e coexistência em que são consideradas. Dessa forma, podemos distinguir os enunciados em análise como enunciados que se associam a um campo político, documento 44 e, outros que se associam ao campo religioso neopentecostal do início do século XXI, presença forte na igreja católica neste momento histórico.

Desse modo, pautada na prática do poder pastoral, a igreja católica assume uma posição-sujeito de quem detém o saber e tem o poder para delegá-lo aos jovens que são objetivados pelos saberes da Pastoral da Juventude. Os enunciados são diferentes sob dois aspectos de análise: como enunciados que se associam a um campo político, documento $44 \mathrm{e}$, outros que se associam ao campo religioso neopentecostal do início do século XXI, presença forte na igreja católica neste momento histórico.

Segundo o Marco Referencial (CNBB, 1998), a formação integral é utilizada para formar o jovem para a reflexão e ação. Essa atuação deve acontecer a partir do embasamento nos referenciais adquiridos a partir de sua participação no grupo de jovens buscando nos termos da pastoral, transformar a estrutura social.

Os depoimentos dos jovens e os enunciados do Marco Referencial da Pastoral da Juventude identifica um conjunto de elementos pensados com o intuito de formar os membros da pastoral para um determinado tipo de postura a ser adotada: "Essas formações me ajudam para me preparar para uma vida mais civilizada. Me dá uma formação de ser um ser melhor e lutador." (N.A - Participante jovem da Pastoral da Juventude diocese de Marabá).

Um conjunto de ações, amparadas principalmente na publicação de materiais, bem como em cursos de formação do jovem deve ser acompanhada pelos assessores, que orientam os passos a serem dados. A assessoria se revela como um trabalho essencial por ser garantidor da perpetuação dos preceitos e normas a serem seguidos

A formação proposta pela Pastoral da Juventude deve resultar numa postura do jovem perante o mundo. A perspectiva é que o jovem formado segundo os preceitos do movimento tenha um grau de entendimento suficiente para agir na igreja e sua sociedade.

É importante salientar que a formação na Pastoral da Juventude não se dá de maneira desinteressada, pelo contrário, possui pressupostos claros e atende a prerrogativas constituídas 
historicamente. Constata-se que o jovem deve se estabelecer enquanto sujeito, a partir dos ensinamentos pastorais.

\section{CONSIDERAÇÕES FINAIS}

O sujeito que é constituído de acordo com os documentos da Pastoral Juventude, é aquele sujeito que está subordinado a ideologia da igreja católica, pois o seu principal objetivo ao ser convocado a participar do movimento pastoral é a consagração e a construção do Reino de Deus, ideologia máxima de toda igreja. Apesar de se considerar como sujeito ativo do processo de evangelização, o jovem torna-se submisso aos dogmas da igreja.

$\mathrm{Na}$ medida em que o jovem adquire os saberes propostos pela Pastoral da Juventude ele vai se constituindo um sujeito objetivado desde que se submeta a reproduzir o discurso da igreja católica via Pastoral da Juventude. Quando acontece esse processo a igreja reconhece o jovem como sujeito construtor da sua própria história. Assim a igreja católica reconhece nos jovens uma forma de se transformar, usando-os como instrumento de renovação de suas práticas discursivas. A partir do momento em que os jovens se inserem no movimento pastoral ele se constitui sujeito de sua história; pois, tem a ilusão de ser protagonista de sua história e deixar de ser alienado dos outros discursos que não sejam o da igreja católica e, acredita que o discurso da igreja não é alienante, mas de libertação.

A formação pastoral entra como propulsora da subjetivação dos jovens que dela participam, na medida em que exige do jovem um outro olhar frente a realidade que está inserido pois, segundo a teoria foucaultiana a objetivação faz o indivíduo dócil, útil e disciplinado, enquanto a subjetivação o transforma em sujeito. Assim a formação da Pastoral da Juventude transforma os jovens em sujeitos objetivados quando são evangelizados e subjetiva esse mesmo jovem na medida em que ele se transforma em agente de evangelização. No entanto, para ser realmente um sujeito subjetivado o jovem deve reconhecer como sua a identidade da Pastoral da Juventude.

Ao assumir o papel de membro da Pastoral da Juventude o jovem é transformado pelo processo de formação integral em sujeito discursivo e simultaneamente esse mesmo jovem é objetivado de acordo com os princípios dessa instituição e subjetivado na medida em que assume a identidade da pastoral da juventude como princípio norteador de sua vida. Nota-se que através do processo de educação na fé, a juventude é controlada por uma porção de normas estabelecidas que são elaboradas de acordo com as exigências da igreja e internalizadas e aceitas pelos jovens da Pastoral da Juventude. 
Embora todo esse processo pedagógico tenha sido produzido com a participação dos jovens, houve a incorporação das recomendações sugeridas pelo bispo, padres, religiosos, religiosas, assessores e assessoras, ou seja, houve uma seleção e controle dos discursos por sujeitos que não são os jovens. Assim as propostas pedagógicas da pastoral da juventude, indica a possibilidade de construção do sujeito que dela fará parte através de um processo de objetivação e subjetivação do jovem. O processo de objetivação e subjetivação do sujeito/jovem faz dele um objeto dócil e útil, disciplinado, de acordo com as normas da Igreja Católica para que este se torne objeto e sujeito de evangelização.

Nesse contexto a proposta de formação da pastoral da juventude, tem por objetivo garantir que o jovem mude sua ação ao participar da pastoral se tornando um transmissor da mensagem da evangelização, conforme os ensinamentos que recebe. A Pastoral da Juventude segue regras estabelecidas por práticas cristãs e políticas, através de relação de micro-poderes que se consolidam nos saberes adquiridos por meio do processo de formação integral.

Em suma, a pastoral da juventude, enquanto instituição responsável pelo cuidado da juventude se coloca em uma posição sujeito salvadora, capaz de conduzir a juventude uma transformação de vida para uma vida melhor. Desse modo, ela tem a ilusão de que é a instituição salvadora da juventude, o que faz produzir um discurso de salvação política, educacional e religiosa.

\section{REFERÊNCIAS}

BORAN. J. Juventude: O grande desafio. 4a ed. São Paulo: Paulinas, 1985.

CNBB- Somos Igreja jovem. $4^{\text {a }}$ ed. São Paulo: Paulinas,2012.

CNBB- Evangelização da Juventude: Desafios e perspectivas pastorais. São Paulo: Paulinas, 2010.

CNBB- Evangelização da Juventude: Desafios e perspectivas pastorais. São Paulo: Paulinas, 2007.

CNBB-Marco Referencial da Pastoral da Juventude do Brasil. Ed. Estudos $n^{\circ}$ 76, São Paulo: Paulus 1998.

CNBB-Processo de formação da PJ - construindo juntos: roteiro para grupos de jovens. São Paulo: CCJ, N/4, 1992.

CNBB - Conferência Nacional dos Bispos do Brasil, Pastoral da Juventude no Brasil. São Paulo: Paulinas, 1986. 
FOUCAULT, Michel. História da Sexualidade. Vol. I. A vontade do saber; Rio de Janeiro: Graal, 2009.

FOUCAULT, Michel. A microfísica do poder (p. 243-276),

Rio de Janeiro: Graal, 2007.

FOUCAULT, Michel. A Ordem do Discurso. Tradução Laura Fraga de Almeida Sampaio. 19a Ed. São Paulo: Loyola 2006.

FOUCAULT, Michel. A arqueologia do saber, tradução de Luiz Felipe Baeta Neves. 6 Ed. Rio de Janeiro, forense universitária, 2000.

Recebido em: 10/07/2019

Aprovado em: 13/08/2019 